12 st. $12 \mathrm{lb}$. (81.6 kg.) for years. Incidentally, I have played games beyond the normal ages: rugger up to 46 , hockey to 63 , and cricket to present age.

My four children (two boys, two girls; boys seem to lag more than girls) have been the same. In some ways this was a great handicap at and beyond the end of school life when trying to compete for scholarships, etc. None of us got scholarships, but all finally got firsts or seconds in university finals. I have observed the same in children of three other long-lived families in which the parents or/and grandparents lived well into the eighties and nineties. I suggest that this might be a subject for research and comment in an editorial. -I am, etc.,

Chulmleigh, N. Devon.

TREFFRY O. THOMPSON.

\section{Vagotomy for Peptic Ulcer}

SIR,-May I make a plea that Mr. Harold Burge clarifies his prose? In his letter (August 12, p. 456) he writes, "Let us be essentially practical and find the proved recurrence rate of vagotomy ..." One can only assume that this must mean the recurrence rate of chronic peptic ulceration following vagotomy, and, having assumed this, one wonders whether he refers to chronic recurrent duodenal ulcer or chronic gastrojejunal ulcer arising de novo following gastrojejunostomy. One then proceeds to wonder how the true incidence of these lesions is to be assessed. Is it to be on clinical features, on radiological appearances, or on gastroscopy? I submit that none of these methods is diagnostically accurate enough to arrive at the truth of the matter, and the probability of false conclusions is therefore considerable.-I am, etc.,

London N.21.

GARDEN HENDRY.

\section{Fusion of Labia Minora}

SIR,-Dr. C. J. Carr, in recording his interesting case of adherent labia minora in a parous woman (July 29, p. 314), asks for enlightenment. I have seen a number of cases of adherent labia minora in young children. From the circumstances, I have regarded the condition as inflammatory in origin. All the cases were sent to me because they were suffering from disturbances of micturition of one kind or another, otherwise they probably would never have reached me.

Under an anaesthetic, I have found that the adherent parts separate quite readily by applying tension on the adhesion with gauze-covered fingers. Post-operative separation is satisfactorily maintained with a simple lanoline dressing.-I am, etc.,

London W.1.

H. P. WinSBURY-White.

\section{Intraperitoneal Haemorrhage from Fibroids}

SIR,-Intraperitoneal haemorrhage from fibromyoma of the uterus gives rise to acute emergency at times. The complication is unusually rare. ${ }^{1}$ Two cases are here reported.

Case 1.-A 19-year-old primigravida was admitted to the Rao J. N. Roy Hospital in June, 1959. She had marked toxaemia of pregnancy at 38 weeks. On admission she complained of vague abdominal pain. Her blood-pressure was $170 / 110$, there was marked oedema of the legs, and the urine was loaded with albumin. The height of the fundus corresponded with the period of amenorrhoea. The baby was presenting cephalically and the foetal heart was not heard with certainty. A few hours after admission it became apparent that the mother's pulse rate was gradually rising, and she became pale. The blood-pressure fell to 140/100. The abdomen was distended and had developed generalized rigidity and tenderness. On palpation the uterine outline was no longer definite. The foetal heart could not be heard any more. The cervix was tubular and closed, and the pouch of Douglas was tender. The child was presenting by vertex and was at the brim. A diagnosis of severe accidental haemorrhage, akin to couvelaire uterus, was made, and laparotomy was performed. The abdomen was full of blood. The baby was delivered quickly by caesarean section, but was dead. The placenta was extracted and there was no evidence of accidental haemorrhage. On the posterolateral surface of the uterus there was a small fibroid, about 2 in. by 2 in. $(5 \mathrm{~cm}$. by $5 \mathrm{~cm}$.). The fibroid was very soft and had a rent on its surface, where a vessel was spurting. There was also oozing from all over its surface. Myomectomy was done and the raw area was covered. Histology showed red degeneration. The patient made an uneventful recovery.

Case 2.-A 32-year-old mother of three children was admitted to hospital in August, 1959, in a collapsed state with severe abdominal pain and slight vaginal bleeding. Her period was overdue by one week. Her blood-pressure was $84 / 60$. The abdomen was rigid, more so in the lower abdomen. Pelvic examination failed to reveal any mass, but was extremely painful. The uterus could not be felt. A provisional diagnosis of ruptured ectopic gestation was made, and laparotomy was performed. The abdomen was full of blood. The tubes and ovaries were normal. A fibroid ( 3 in. by 3 in. $-7.5 \mathrm{~cm}$. by $7.5 \mathrm{~cm}$.) on the anterior surface of the uterus was partly detached from its bed, leaving a small cavity as if someone had been trying to enucleate it. The torn area was bleeding freely. Myomectomy was done and the raw area was covered up. The patient recovered uneventfully.

Marrow $^{2}$ has reported intraperitoneal haemorrhage from spontaneous rupture of a varicose vein of the uterus during pregnancy where there was no fibroid. Recently Bigby ${ }^{3}$ and Badaway ${ }^{1}$ have reported two cases similar to our own. It appears, therefore, that intraperitoneal haemorrhage from the ruptured uterine veins, whether over a fibroid or from varicosity, may precipitate an acute emergency. Trauma, increased intra-abdominal pressure, and vascular congestion during menstruation have all been blamed as precipitating factors. In one of my cases red degeneration of the fibroid together with toxaemia of pregnancy precipitated the crisis. The cause of bleeding in the other case is difficult to explain. It seems likely that the fibroid was intramural to start with, and that the uterus, treating it as a foreign body, was trying to expel it. When the fibroid was partly detached from its bed free intraperitoneal bleeding occurred, giving rise to shock and peritoneal irritation.

The treatment is myomectomy in most cases, as these patients are gravely ill and also comparatively young.

I am grateful to the C.M.O.H. and the D.M.O., Murshidabad, for their kind permission to use the case records.

-I am, etc.,

Rao J. N. Roy Hospital, Probhat Kumar Choudhuri. Murshidabad, West Bengal. India.

\section{REPERENCES}

1 Badaway, A. H., Brit. med. J., 1961, 1, 717.

2 Marrow, A. E., J. Obst. Gynaec. Brit. Emp., 1960, 67, 792. 3 Bigby, M. A. M., Brit. med. J., 1960, 2, 580.

\section{Betamethasone}

SIR,-Dr. R. O. Gillhespy's experiences (August 12, p. 454) with the use of betamethasone in rheumatoid arthritis are at considerable variance with those which 